\title{
Bandwidth enhancement and miniaturization of circular-shaped microstrip antenna based on beleved half-cut structure for MIMO $2 \times 2$ application
}

\author{
Teguh Firmansyah ${ }^{1}$, Supriyanto Praptodiyono ${ }^{2}$, Herudin $^{3}$, Didik Aribowo ${ }^{4}$, Syah Alam ${ }^{5}$, \\ Dian Widi Astuti ${ }^{5}$, Muchamad Yunus ${ }^{7}$ \\ ${ }^{1,2,3}$ Department of Electrical and Engineering, Universitas Sultan Ageng Tirtayasa, Indonesia \\ ${ }^{4}$ Department of Electrical Engineering Vocational Education, Universitas Sultan Ageng Tirtayasa, Indonesia \\ ${ }^{5}$ Department of Electrical Engineering, Universitas 17 Agustus 1945 Jakarta, Indonesia \\ ${ }^{6}$ Department of Electrical Engineering, University of Mercu Buana, Indonesia \\ ${ }^{7}$ Department of Electrical Engineering, University of Pakuan, Indonesia
}

\begin{tabular}{l}
\hline \hline Article Info \\
\hline Article history: \\
Received Aug 6, 2018 \\
Revised Nov 16, 2018 \\
Accepted Dec 26, 2018 \\
\hline
\end{tabular}

Keywords:

Antenna

Bandwidth

Beleved

Microstrip

MIMO

\begin{abstract}
In this paper, circular-shaped microstrip antenna was simulated, fabricated, and measured accordingly. As the novelty, to enhance bandwidth and reduce antenna size, beleved half-cut microstrip structure is proposed. Further, this proposed antenna structure will be applied to multiple input multiple output (MIMO) antenna $2 \times 2$. Therefore, this research was investigated conventional circular shape antenna (CCSA), circular shaped beleved antenna (CSBA), and MIMO circular shaped beleved antenna (MIMO-CBSA) as Model 1, Model 2, and Model 3, respectively. An FR4 substrate with er=4.4, thickness $\mathrm{h}=1.6 \mathrm{~mm}$, and $\tan \mathrm{d}=0.0265$ was used. The simulation has been conducted using Advanced Design System (ADS). The antenna CCSA/CSBA/MIMOCBSA achieve $1.831 \mathrm{GHz} / 2.265 \mathrm{GHz} / 2.256 \mathrm{GHz},-15.13 \mathrm{~dB} /-17.37 \mathrm{~dB} /-17.25$ $\mathrm{dB}, 1.42 / 1.31 / 1.33$, and $1.474 / 2.332 / 2.322$ for center frequency, reflection coefficient, VSWR, and bandwidth, respectively. This antenna has a size $63 \times 90 \mathrm{~mm}$ and $51.5 \times 90 \mathrm{~mm}$ for CCSA (Model 1) and CSBA (Model 2), respectively. After the structure of MIMO $2 \times 2$ was applied, the size of antenna MIMO-CBSA (Model 3) became $180 \mathrm{~mm} \times 180 \mathrm{~mm}$ with a mutual coupling $\left(\mathrm{S}_{21}\right)=-26.18 \mathrm{~dB}$ and mutual coupling $\left(\mathrm{S}_{31}\right)=-26.41 \mathrm{~dB}$. The result showed that proposed antenna CSBA (Model 2) has wider-bandwidth of $58,2 \%$ and smaller-size of $18.2 \%$. Furthermore, after CSBA (Model 2) structure was applied to MIMO $2 \times 2$ (Model 3 ) and the MIMO antenna obtain good mutual coupling $(<-15 \mathrm{~dB})$. Moreover, the measured results are good agreement with the simulated results. In conclusion, all of these advantages make it particularly valuable in multistandard antenna applications design such as GSM950, WCDMA1800, LTE2300, and WLAN2400.
\end{abstract}

Copyright (C) 2019 Institute of Advanced Engineering and Science. All rights reserved.

\section{Corresponding Author:}

Teguh Firmansyah,

Department of Electrical and Engineering,

University of Sultan Ageng Tirtayasa,

Jl. Jend. Sudirman. Km. 3. Cilegon. Banten. 42435, Indonesia.

Email: teguhfirmansyah@untirta.ac.id

\section{INTRODUCTION}

In recent years, microstrip patch antenna technology is widely used. The microstrip patch antenna has advantages such as low fabrication cost, light in weight, capable of supporting multiple frequency bands, easily etched on any PCB and integrated them with MICs or MMICs [1-3]. However, it has disadvantages such as low gain, large PCB structure, and narrow bandwidth due to conductor losses, surface wave losses, 
and dielectric losses $[4,5]$. Several studies investigating bandwidth enhancement of microstrip antenna have been carried out by [6, 7]. The proposed methods include defected ground structure (DGS) [6], electromagnetic band gap (EBG) [7,8], parasitic patch [9, 10], metamaterial [11], metamaterial bilayer substrates (MBS) [12], monopole slot [13], T-shaped slot [14], cylindrical dielectric slot (CDS) [15], polymeric grid [16], spiral split ring (SSR) [17], Jerusalem cross-shaped [18], and characteristic modes [19].

The DGS method was proposed by Marotkar [6], it is realized by etching the ground plane so the current distribution in the ground plane is disturbed. As the results, the antenna has a wide bandwidth of 302 $\mathrm{MHz}$ with center frequency of $2.4 \mathrm{GHz}$, and reflection coefficient of $-23.26 \mathrm{~dB}$. Furthermore, Gupta [7] and Hadarig [8] investigated bandwidth enhancement of microstrip patch antennas by implementing EBG structures. This proposed antenna has a center frequency of $10 \mathrm{GHz}$ and $2.4 \mathrm{GHz}$ for X-band Radar and VHF RFID, respectively. Then, to reduce the size of the antenna, Rothwell and Raoul O [21] proposed a metamaterial structure. The metamaterial microstrip structure has advantages such as compact size and broadband. However, the structure has complex geometry, and it is difficult to fabricate. Then, H. Mosallaei and K. Sarabandi [22] proposed bandwidth enhancement by using a reactive impedance substrate (RIS). This method succeeds to increase the bandwidth of the antenna and reduce antenna size.

Moreover, a fascinating method was proposed by Mohamadi [18]. It investigated the bandwidth enhancement of antenna for Long Term Evolution (LTE) technology with multiple input multiple output (MIMO) application. He introduced the basic modes method, this method successfully to enhance the bandwidth of the antenna, but it was still a drawback such as complex microstrip structure. Other methods include, G-shaped band-notched antenna [23], dielectric resonator antenna (DRA) [24], and U-shaped slot antenna [25]. The DRA antenna that is proposed by [24] has good bandwidth. However, the antenna structure is still large.

As the novelty, to enhance bandwidth and reduce antenna size, beleved half-cut microstrip structure is proposed in this paper. Further, this proposed antenna structure will be applied to multiple input multiple output $(\mathrm{MIMO})$ antenna $2 \times 2$. Therefore, this research was investigated conventional circular shape antenna (CCSA), circular shaped beleved antenna (CSBA), and MIMO circular shaped beleved antenna (MIMOCBSA) as Model 1, Model 2, and Model 3, respectively. An FR4 substrate with er=4.4, thickness $\mathrm{h}=1.6 \mathrm{~mm}$, and $\tan \mathrm{d}=0.0265$ was used. In brief, Table 1 . provides the research position of this paper compare to another research of bandwidth enhancement and miniaturization of the antenna.

Table 1. The Research Position of Bandwidth Enhancement and Miniaturization of the Antenna

\begin{tabular}{|c|c|c|c|c|c|c|}
\hline Ref. no & Method & Center Freq. & $\begin{array}{c}\text { Wireless } \\
\text { Technology }\end{array}$ & $\begin{array}{c}\text { Bandwidth } \\
\text { Enhancement }\end{array}$ & $\begin{array}{l}\text { Miniatu- } \\
\text { rization }\end{array}$ & $\begin{array}{c}\text { MIMO } \\
\text { Application }\end{array}$ \\
\hline$[6]$ & DGS & $2.4 \mathrm{GHz}$ & WLAN & yes & - & - \\
\hline [7] & EBG & $10 \mathrm{GHz}$ & X-band Radar & yes & - & - \\
\hline [8] & EBG & $2.4 \mathrm{GHz}$ & RFID & yes & - & - \\
\hline [9] & Parasitic Patch & $8.5 \mathrm{GHz}$ & X-band & yes & - & - \\
\hline [10] & Parasitic Patch & $120 \mathrm{MHz}$ & VHF RFID & yes & & \\
\hline [11] & Metamaterial & $1.9 \mathrm{GHz}$ & GSM & yes & - & - \\
\hline [12] & Metamaterial Bilayer & $2.6 \mathrm{GHz}$ & LTE & yes & - & - \\
\hline [13] & Monopole Slot & $4.4 \mathrm{GHz}$ & WiMAX & yes & - & - \\
\hline [14] & T-shaped Slot & $6.7 \mathrm{GHz}$ & UWB & yes & - & - \\
\hline [15] & Dielectric Slot & $11.25 \mathrm{GHz}$ & X-band & yes & - & - \\
\hline [16] & Polymeric Grid & $26.8 \mathrm{GHz}$ & $5 \mathrm{G}$ & yes & - & - \\
\hline [17] & Spiral Split Ring & $5.8 \mathrm{GHz}$ & WLAN & yes & - & - \\
\hline [18] & Jerusalem Cross-Shaped & $5.8 \mathrm{GHz}$ & WLAN & yes & - & - \\
\hline [19] & Characteristic Modes & $1.9 \mathrm{GHz}$ & LTE & yes & & yes \\
\hline [20] & Parasitic Patch & $2.6 \mathrm{GHz}$ & LTE & yes & - & yes \\
\hline [21] & Metamaterial & $2.6 \mathrm{GHz}$ & LTE & - & yes & - \\
\hline [22] & RIS & $1.9 \mathrm{GHz}$ & WCDMA & yes & yes & - \\
\hline [23] & G-shaped band-notched & $7.75 \mathrm{GHz}$ & UWB & - & - & yes \\
\hline [24] & DRA & $30 \mathrm{GHz}$ & $5 \mathrm{G}$ & - & - & yes \\
\hline [25] & U-shaped Slot & $3 \mathrm{GHz}$ & Selular & - & - & yes \\
\hline $\begin{array}{l}\text { This } \\
\text { paper }\end{array}$ & $\begin{array}{l}\text { Circular-Shaped } \\
\text { with Beleved } \\
\text { Halfcut Structure }\end{array}$ & $2.175 \mathrm{GHz}$ & $\begin{array}{l}\text { GSM, WCDMA, } \\
\text { LTE, and WLAN }\end{array}$ & yes & yes & yes \\
\hline
\end{tabular}

This rest of this paper is detailed as follows. In Section 2, the proposed circular shaped beleved antenna and MMO circular shaped beleved antenna are presented. The detail of numerical simulation was also described in Section 2. Furthermore, the measurement results of the fabricated antenna and the comparison with simulation result was explained in Section 3. Finally, Section 4 concludes this research. 


\section{RESEARCH METHOD}

In this section, the proposed circular shaped beleved antenna and MMO circular shaped beleved antenna were designed. Figure 1(a), Figure 1(b), Figure 1(c), Figure 1(d), and Figure 1(e) show conventional circular shape antenna (CSSA) [Model-1], front view of CCSA, circular shaped beleved antenna (CSBA) [Model-2], front view of CBSA, MIMO circular shaped beleved antenna (CSBA) [Model-3], respectively.

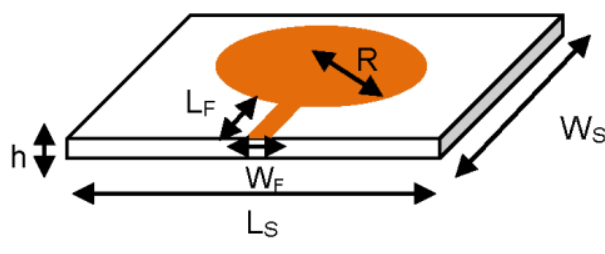

(a)

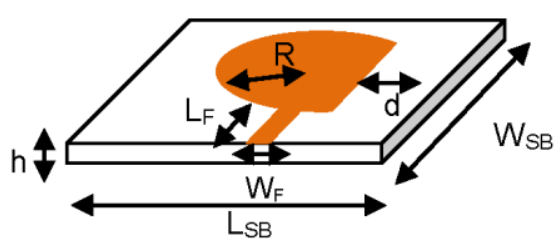

(c)

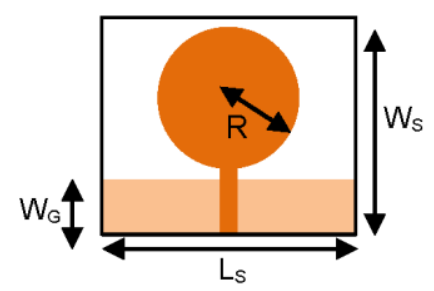

(b)

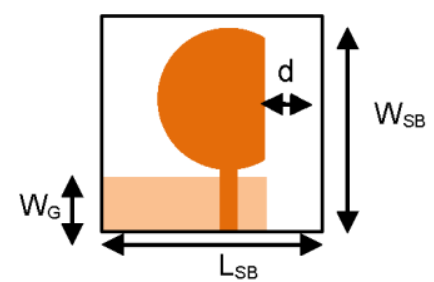

(d)

Patch
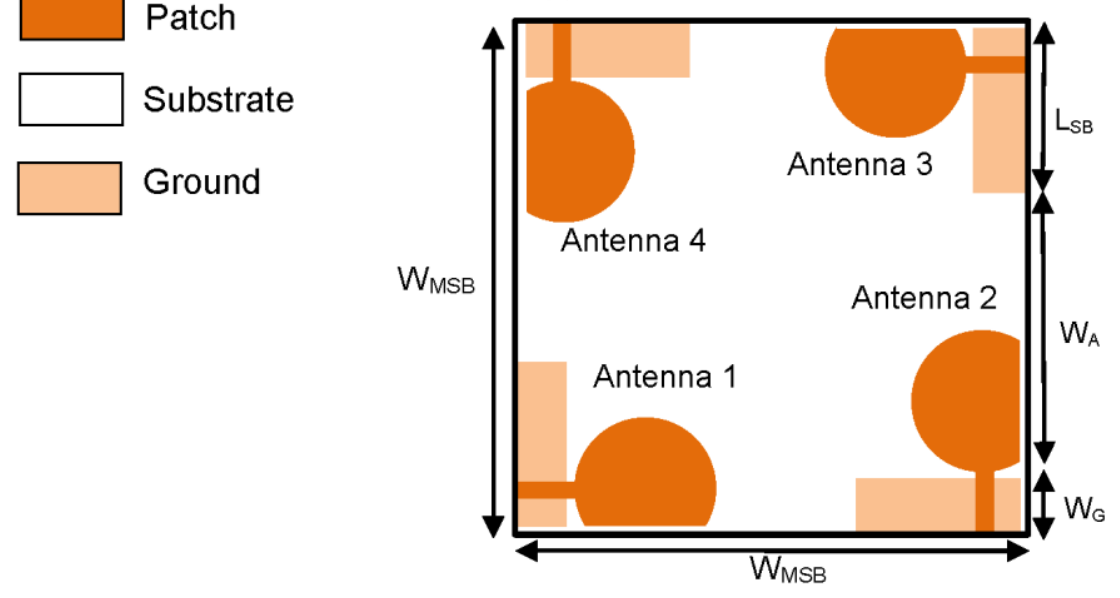

(e)

Figure 1. (a) Conventional Circular Shape Antenna (CCSSA) [Model-1], (b) Front view of Conventional Circular Shape Antenna, (c) Circular Shaped Beleved Antenna (CSBA) [Model-2], (d) Front view of Circular

Shaped Beleved Antenna, (e) MIMO Circular Shaped Beleved Antenna (MIMO-CSBA) [Model-3]

The radius of circular-shaped microstip patch antenna is formulated by [26], [27]:

$R=\frac{F}{\sqrt{1+\frac{2 h}{\pi \varepsilon_{r}}\left[\ln \left(\frac{\pi F}{2 h}\right)+1.7726\right]}}$

Where

$$
F=\frac{8.791 \times 10^{9}}{f_{r} \sqrt{\varepsilon_{r}}}
$$


with $h=$ thickness of substrate $(\mathrm{cm}), \varepsilon r=$ permittivity of substrate, and $f_{r}=$ resonant frequency $(\mathrm{Hz})$. A direct feeding method was used in this paper. Moreover, the impedance characteristic $\left(\mathrm{Z}_{0}\right)$ can be determined by the ratio of a thickness of substrate $(h)$ and its width $(W)$ [28].

When $Z_{0} \sqrt{\epsilon_{r e}}>89.91, \mathrm{~W} / \mathrm{h}$ ratio is given by [29], [30]:

$W / h=\frac{8 \exp (A)}{\exp (2 A)-2}$

when $Z_{0} \sqrt{\epsilon_{r e}} \leq 89.91, \mathrm{~W} / \mathrm{h}$ ratio is given by [29], [30]:

$W / h=\frac{2}{\pi}\left\{B-1-\ln (2 B-1)+\frac{\epsilon_{r}-1}{2 \epsilon_{r}}\left[\ln (B-1)+0.39-\frac{0.61}{\epsilon_{r}}\right]\right\}$

where

$A=\frac{Z_{0}}{60}\left\{\frac{\epsilon_{r}+1}{2}\right\}^{1 / 2}+\frac{\epsilon_{r}-1}{\epsilon_{r}+1}\left\{0.23+\frac{0,11}{\epsilon_{r}}\right\}$

$B=\frac{60 \pi^{2}}{Z_{0} \sqrt{\varepsilon_{r}}}$

$\epsilon_{r e}=\frac{\epsilon_{r}+1}{2}+\frac{\epsilon_{r}-1}{2} F\left(\frac{W}{h}\right)$

Furthermore, the conductivity loss $\left(\propto_{C}\right)$ of microstrip transmission line feeding is given by [29], [30];

$\alpha_{C}= \begin{cases}1,38 D \frac{R_{S}}{h Z_{0}} \frac{32-(W / h)^{2}}{32+(W / h)^{2}} & \left(\frac{W}{h} \leq 1\right) \\ 6,1 \times 10^{-5} D \frac{R_{S} Z_{0} \epsilon_{r e}(f)}{h}\left[W_{e} / h+\frac{0,667 W / h}{W_{e} / h+1,444}\right] & \left(\frac{W}{h} \geq 1\right)\end{cases}$

where

$D=1+\frac{h}{W}\left\{1+\frac{1,25}{\pi} \ln \frac{4 \pi W}{t}\right\}$

with

$R_{S}=\sqrt{\pi f \mu_{0} \rho_{C}}$

$\rho_{C}=$ resistivity of the conductor,

$f=$ frequency $(\mathrm{Hz})$, and

$\mu_{0}=4 \pi \times 10^{-7} \mathrm{~N} \cdot \mathrm{A}^{-2}$ is the magnetic permeability of free space,

The numerical simulation of the antenna parameters has been conducted by using Advanced Design System (ADS). The FR4 substrate with $\varepsilon r=4.4$, thickness $\mathrm{h}=1.6 \mathrm{~mm}$, and tan $\mathrm{d}=0.0265$ was used. Figure 2(a) shows the extracted reflection coefficient with varied R. The data shows that by modifying the radius (R), the reflection coefficient can be tuned. However, for $\mathrm{R}=22 \mathrm{~mm}$ and $\mathrm{R}=24 \mathrm{~mm}$, the antenna is not resonance. Furthermore, Figure 2(b) shows the voltage standing wave ratio (VSWR) value by varied radius (R). The simulation result shows that VSWR value is better than 2 at $\mathrm{R}=28 \mathrm{~mm}$ and $\mathrm{R}=30 \mathrm{~mm}$. 


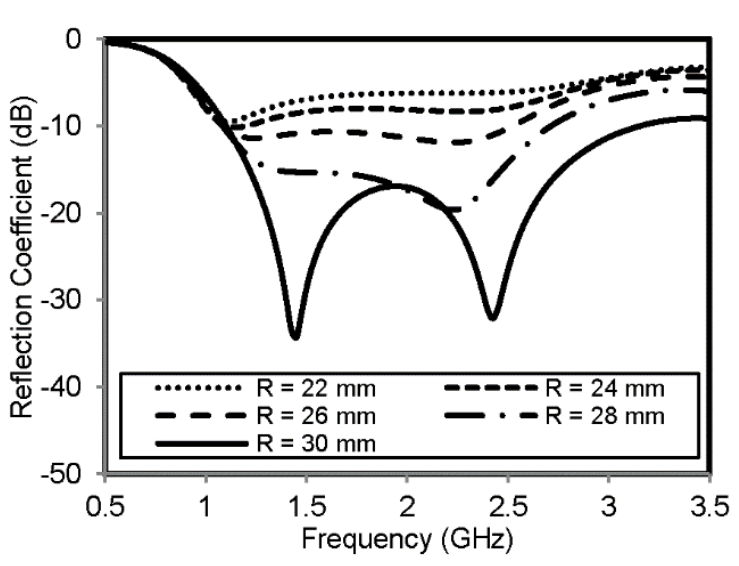

(a)

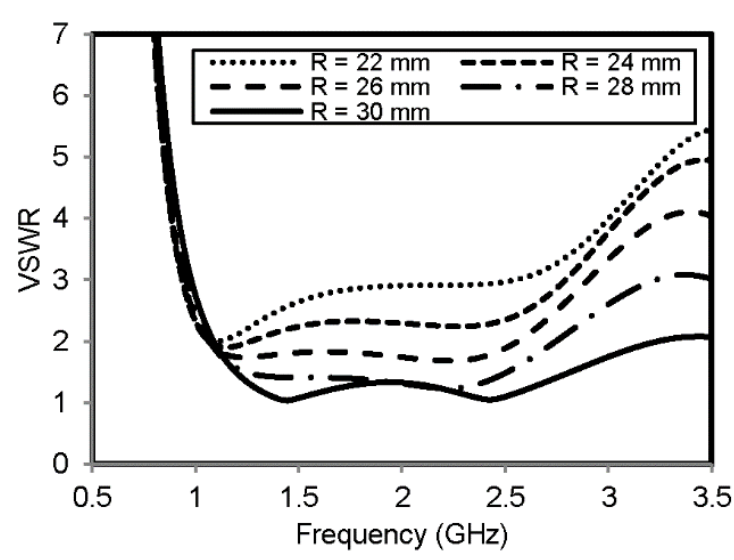

(b)

Figure 2. (a) The extracted reflection coefficient with varied $\mathrm{R}(\mathrm{mm})$; (b) The extracted voltage standing wave ratio (VSWR) with varied $\mathrm{R}(\mathrm{mm})$

Figure 3(a) and Figure 3(b) illustrate the reflection coefficient with varied $\mathrm{W}_{\mathrm{G}}$ and voltage standing wave ratio (VSWR) with varied $W_{G}$, respectively. From the data in Figure 3(a), we can see that the $W_{G}$ is essential parameters to make the antenna resonate. The Figure 3(a) shows that by increasing the $\mathrm{W}_{\mathrm{G}}(\mathrm{mm})$, the antenna will be more resonate. Moreover, Figure 3(b) shows clearly trend that the VSWR of the antenna is better than 2 (two) for $\mathrm{W}_{\mathrm{G}}$ is longer than $28 \mathrm{~mm}$. However, the dimension of this antenna is large. The next step explains the miniaturization process.

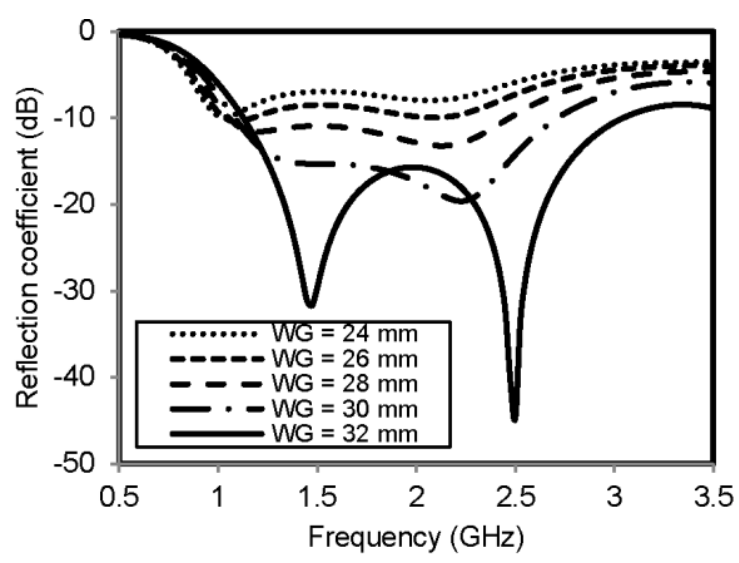

(a)

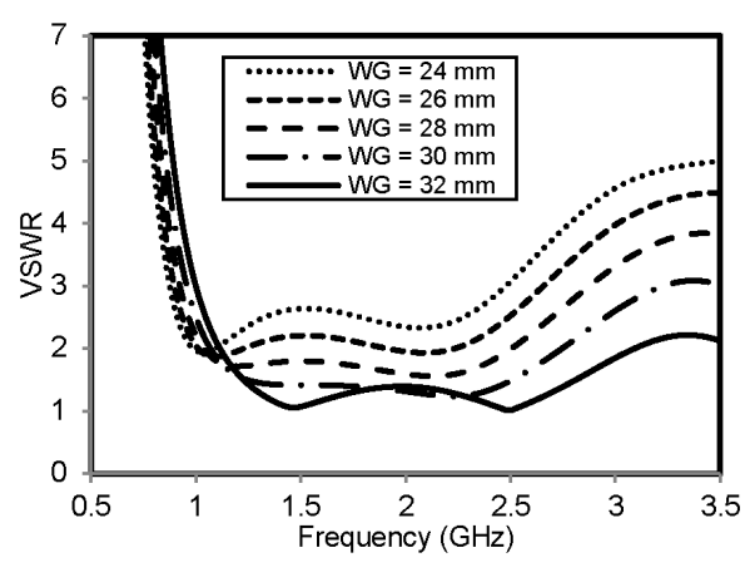

(b)

Figure 3. (a) The extracted reflection coefficient with varied $\mathrm{W}_{\mathrm{G}}(\mathrm{mm})$; (b) The extracted voltage standing wave ratio (VSWR) with varied $\mathrm{W}_{\mathrm{G}}(\mathrm{mm})$

In this paper, the bandwidth enhancement and miniaturization of the antenna is obtained by the beleved method as shown in Figure 1(b) and Figure 1(c). The beleved method was applied by cut one side of the antenna, partially. Furthermore, the size of the antenna will be reduced by $\mathrm{d}(\mathrm{mm})$. Moreover, the result of numerical simulation based on the beleved method is depicted in Figure 4(a) and Figure 4(b). Figure 4(a) illustrates the extracted reflection coefficient with varied $\mathrm{d}(\mathrm{mm})$. Base on Figure 4(a), the data shows that at $\mathrm{d}=10 \mathrm{~mm}$ produce large bandwidth. However for $\mathrm{d}=10 \mathrm{~mm}$ at the frequency of $2.8 \mathrm{GHz}$, the reflection coefficient is higher than $-10 \mathrm{~dB}$ at frequency of $2.8 \mathrm{GHz}$. Therefore, the value $\mathrm{d}=10 \mathrm{~mm}$ is not chosen because the reflection coefficient is too high. Therefore, the data shows that the largest bandwidth is generated at $\mathrm{d}=8 \mathrm{~mm}$. This result is also indicated in Figure $4(\mathrm{~b})$ which presents the extracted center frequency and bandwidth with varied $\mathrm{d}(\mathrm{mm})$. For instance, the circular shaped beleved antenna (CSBA) [Model-2] is represented by the antenna with $\mathrm{d}=8 \mathrm{~mm}$ and the conventional circular shape antenna (CCSA) [Model-1] is represented by the antenna with $\mathrm{d}=0 \mathrm{~mm}$. 


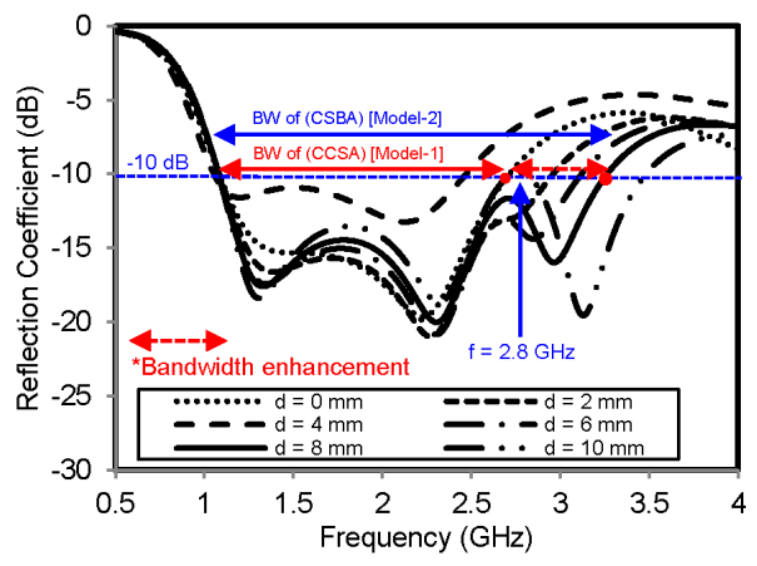

(a)

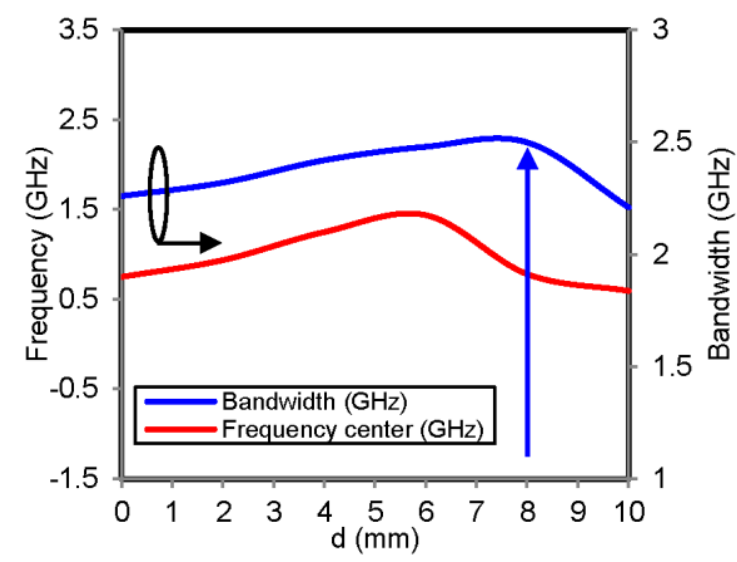

(b)

Figure 4. (a) The extracted reflection co efficient with varied d (mm); (b) The extracted frequency center and bandwidth with varied $\mathrm{d}(\mathrm{mm})$

The next step is to apply the CSBA [Model-2] to MIMO-CSBA [Model-3] antenna as shown in Figure 1(e). Furthermore, Figure 5(a) shows the extracted reflection coefficient with different $\mathrm{W}_{\mathrm{SMB}}(\mathrm{mm})$ and Figure 5(b) illustrates the extracted voltage standing wave ratio (VSWR) with varied $\mathrm{W}_{\mathrm{SMB}}(\mathrm{mm})$. Figure 5(a) shows a clear illustration that the reflection coefficient is stable for the different length of $\mathrm{W}_{\mathrm{SMB}}$ and it shows that the reflection coefficient values are lower than $-10 \mathrm{~dB}$. However, the reflection coefficient for $\mathrm{W}_{\mathrm{SMB}}=180 \mathrm{~mm}$ generates lower bandwidth than others. Furthermore, it appears from Figure 5(b) that the VSWR values are still lower than 2 (two). This data shows that the antenna is working properly with good performance.

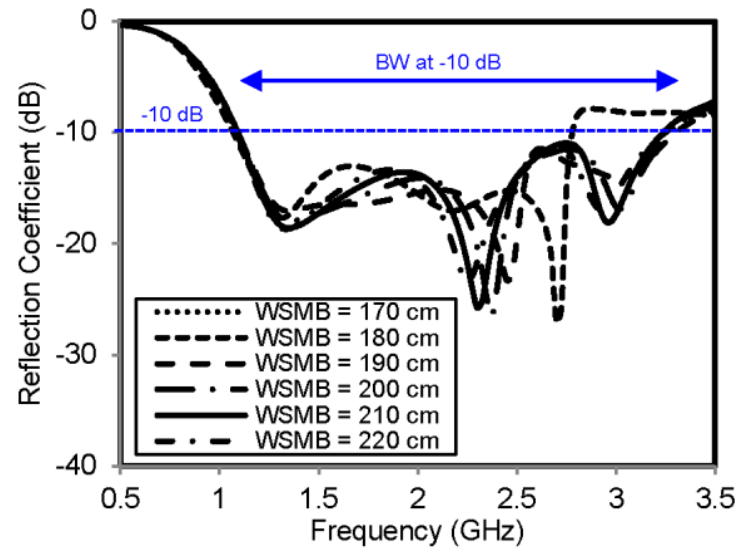

(a)

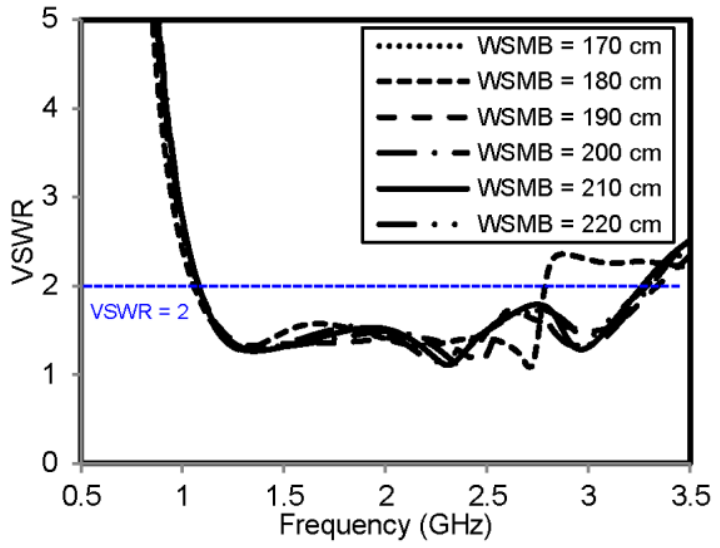

(b)

Figure 5. (a) The extracted reflection coefficient with varied $\mathrm{W}_{\mathrm{SMB}}(\mathrm{mm})$; (b) The extracted voltage standing wave ratio (VSWR) with varied $\mathrm{W}_{\mathrm{SMB}}(\mathrm{mm})$

The numerical simulation result of mutual coupling MIMO antenna is shown in Figure 6(a) and Figure 6(b). Figure 6(a) exhibits the extr acted mutual coupling $\left(\mathrm{S}_{21}\right)$ with varied $\mathrm{W}_{\mathrm{SMB}}(\mathrm{mm})$ and Figure $6(\mathrm{~b})$ illustrates the extracted mutual coupling $\left(\mathrm{S}_{31}\right)$ with varied $\mathrm{W}_{\mathrm{SMB}}(\mathrm{mm})$. The mutual coupling value of $S_{21}(\mathrm{~dB})$ and $\mathrm{S}_{31}(\mathrm{~dB})$ demonstrate the coupling between Antena 1 to Antenna 2 and Antena 1 to Antenna 3, respectively. The coupling coefficient is lower than $-15 \mathrm{~dB}$ almost over the whole band which shows a good isolation performance. However, the coupling coefficient for $\mathrm{W}_{\mathrm{SMB}}=180 \mathrm{~mm}$ is higher than $-15 \mathrm{~dB}$ at the frequency of $2.8 \mathrm{GHz}$. So, the $\mathrm{W}_{\mathrm{SMB}}=180 \mathrm{~mm}$ cannot be chosen. The distace between antenna effects on mutual coupling. The mutual coupling can be decreased by increasing the distance between the MIMO antennas. However, the size of the antennas cannot be made too large. 


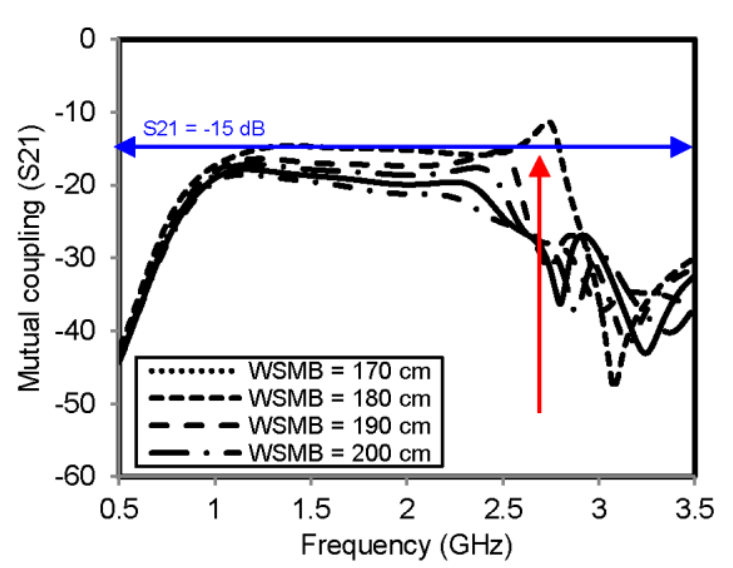

(a)

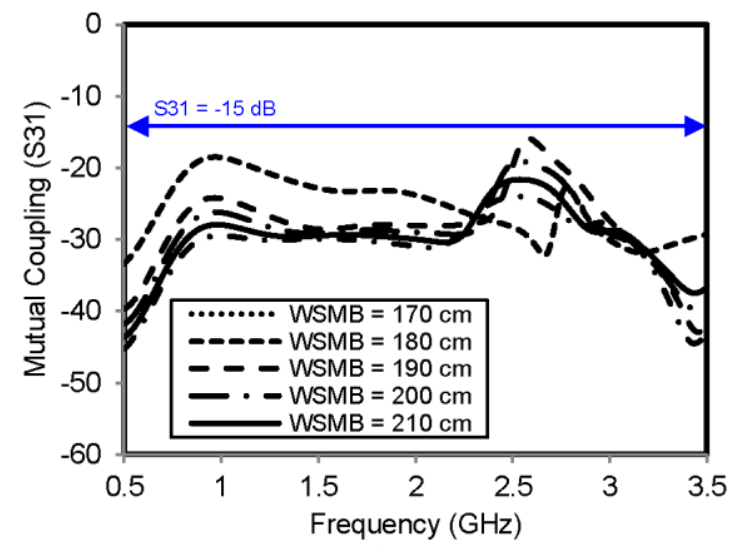

(b)

Figure 6. (a) The extracted mutual coupling $\left(\mathrm{S}_{21}\right)$ with varied $\mathrm{W}_{\mathrm{SMB}}(\mathrm{mm})$; (c) The extracted mutual coupling $\left(\mathrm{S}_{31}\right)$ with varied $\mathrm{W}_{\mathrm{SMB}}(\mathrm{mm})$

\section{RESULTS AND ANALYSIS}

To verify the simulation result, the measurement of the antenna prototype must be carried out. The photograph of the fabricated proposed antenna is depicted in Figure 7(a), Figure 7(b), and Figure 7(c). Figure 7(a) shows the photograph of conventional circular shape antenna (CCSA) [Model-1], and Figure 7(b) illustrates the photograph of circular shaped beleved antenna (CSBA) [Model-2]. Furthermore, Figure 7(c) presents the photograph MIMO circular shaped beleved antenna (MCSBA) [Model-3]. The FR4 substrate with $\varepsilon r=4.4$, thickness $\mathrm{h}=1.6 \mathrm{~mm}$, and $\tan \mathrm{d}=0.0265$ was used. The simulation and optimization has been conducted using Advanced Design System (ADS). The detailed geometric parameters are $\mathrm{R}=28 \mathrm{~mm}$, $\mathrm{L}_{\mathrm{S}}=63 \mathrm{~mm}, \mathrm{~W}_{\mathrm{S}}=90 \mathrm{~mm}, \mathrm{~W}_{\mathrm{G}}=30 \mathrm{~mm}, \mathrm{~L}_{\mathrm{F}}=34 \mathrm{~mm}, \mathrm{~W}_{\mathrm{F}}=3 \mathrm{~mm}, \mathrm{~d}=8 \mathrm{~mm}, \mathrm{~L}_{\mathrm{SB}}=51.5 \mathrm{~mm}, \mathrm{~W}_{\mathrm{SB}}=90 \mathrm{~mm}$, $\mathrm{W}_{\mathrm{MSB}}=190 \mathrm{~mm}$, and $\mathrm{W}_{\mathrm{A}}=98.5 \mathrm{~mm}$, Moreover, the full size of the PCB board is $190 \times 190 \mathrm{~mm}^{2}$.

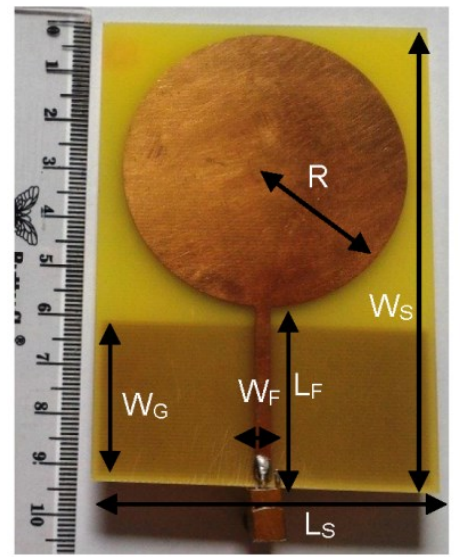

(a)

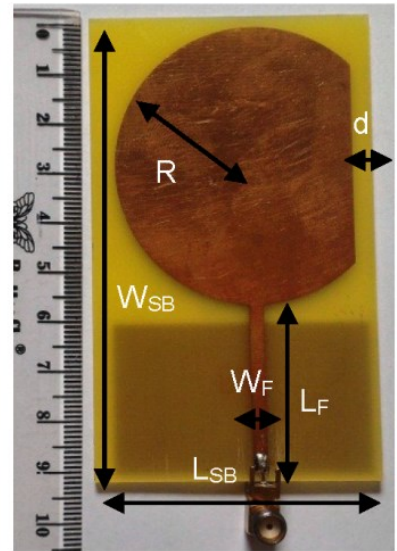

(b)

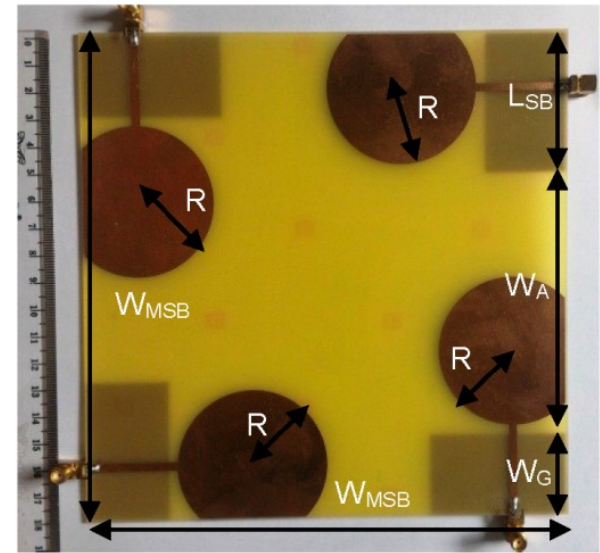

(c)

Figure 7. Photograph of (a) conventional circular shape antenna (CCSA) [Model-1], (b) circular shaped beleved antenna (CSBA) [Model-2], (c) MIMO circular shaped beleved antenna (MCSBA) [Model-3]

Figure 8(a) shows the comparison between simulated and measured of reflection coefficient of CCSA antenna dan CSBA antenna. The simulated/measured of CCSA antenna [Model-1] achieves lower frequency $=1.093 \mathrm{GHz} / 1.094 \mathrm{GHz}$, upper frequency $=2.719 \mathrm{GHz} / 2.568 \mathrm{GHz}$, center frequency $=1.906$ $\mathrm{GHz} / 1.831 \mathrm{GHz}$, bandwidth $=1.626 \mathrm{GHz} / 1.474 \mathrm{GHz}$, and reflection coefficient $=-16.39 \mathrm{~dB} /-15.13 \mathrm{~dB}$ with the size of CCSA antenna has $63 \times 90 \mathrm{~mm}$. Furthermore, the simulated/measured of CBSA antenna [Model-2] achieves lower frequency $=1.051 \mathrm{GHz} / 1.090 \mathrm{GHz}$, upper frequency=3.299 $\mathrm{GHz} / 3.422 \mathrm{GHz}$, center frequency=2.175 GHz/2.265 GHz, bandwidth=2.248 GHz/2.332 GHz, and reflection 
coefficient $=-17.99 \mathrm{~dB} / 17.37 \mathrm{~dB}$ with the size of CSBA antenna has $51.5 \times 90 \mathrm{~mm}$. Moreover, Figure $8(\mathrm{~b})$ shows the comparison between simulated and measured of VSWR. The simulated/measured of CCSA antenna [Model-1] achieves VSWR=1.35/1.42, and the simulated/measured of CSBA antenna [Model-2] achieves VSWR=1.28/1.31. Base on the measurement performance, both antennas can work as expected. However, the comparison result showed that proposed antenna CSBA [Model 2] has wider-bandwidth of $58,2 \%$ and smaller-size of $18.2 \%$.

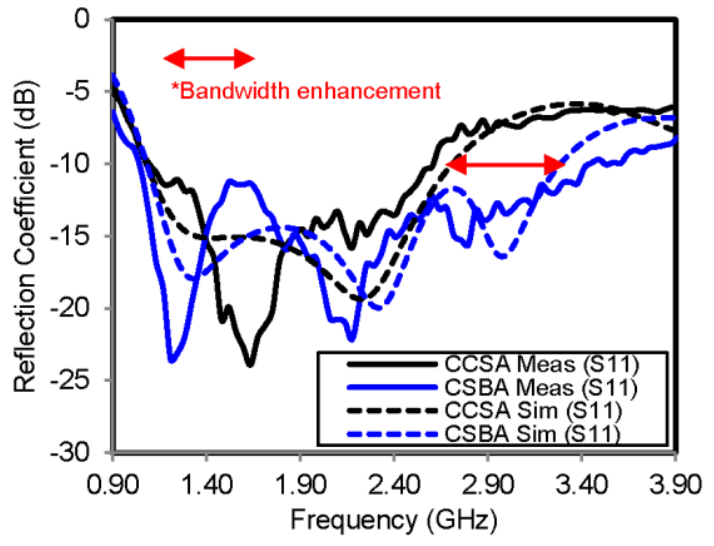

(a)

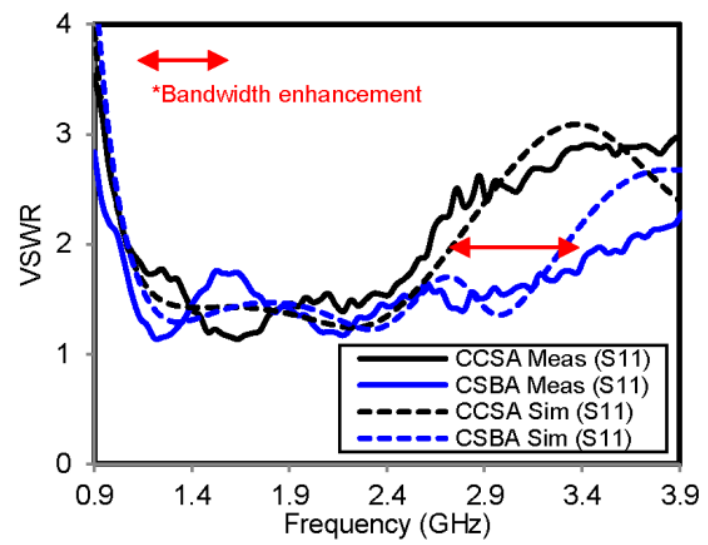

(b)

Figure 8. (a) The comparison between simulated and measured of reflection coefficient; (b) The comparison between simulated and measured of VSWR

Figure 9(a) exhibits the comparison of gain $(\mathrm{dBi})$, directivity $(\mathrm{dBi})$, efficiency $(\%)$. The gain of CCSA [Model 1]/CSBA [Model 2] antenna has $1.58 \mathrm{dBi} / 1.56 \mathrm{dBi}, 3.61 \mathrm{dBi} / 2.29 \mathrm{dBi}, 2.44 \mathrm{dBi} / 2.27 \mathrm{dBi}$, and $2.47 \mathrm{dBi} / 2.34 \mathrm{dBi}$ for frequency of $0.95 \mathrm{GHz}, 1.85 \mathrm{GHz}, 2.35 \mathrm{GHz}$, and $2.45 \mathrm{GHz}$, respectively. Furthermore, the directivity of CCSA [Model 1]/CSBA [Model 2] antenna has $2.34 \mathrm{dBi} / 2.32 \mathrm{dBi}$, $2.36 \mathrm{dBi} / 3.54 \mathrm{dBi}, 3.99 \mathrm{dBi} / 3.74 \mathrm{dBi}$, and $4.09 \mathrm{dBi} / 3.84 \mathrm{dBi}$ for frequency of $0.95 \mathrm{GHz}, 1.85 \mathrm{GHz}$, $2.35 \mathrm{GHz}$, and $2.45 \mathrm{GHz}$, respectively. The efficiency of CCSA [Model 1]/CSBA [Model 2] antenna has $83.99 \% / 83.92 \%, 75.12 \% / 74.92 \%, 70.10 \% / 71.25 \%$, and $68.95 \% / 70.89 \%$ for frequency of $0.95 \mathrm{GHz}$, $1.85 \mathrm{GHz}, 2.35 \mathrm{GHz}$, and $2.45 \mathrm{GHz}$, respectively. Moreover, Figure 9(b) shows the comparison between simulated and measured of mutual coupling $\left(\mathrm{S}_{21}\right)$ and $\left(\mathrm{S}_{31}\right)$. The simulated/measured of mutual coupling of MIMO-CBSA [Model-3] antenna are $-16.15 \mathrm{~dB} /-26.18 \mathrm{~dB}$ and $-27.11 \mathrm{~dB} /-26.41 \mathrm{~dB}$ for mutual coupling $\left(\mathrm{S}_{21}\right)$ and mutual coupling $\left(\mathrm{S}_{31}\right)$, respectively. The MIMO antenna obtain very good mutual coupling $(<-15 \mathrm{~dB})$. Moreover, the measured results are in a good agreement with the simulated results.

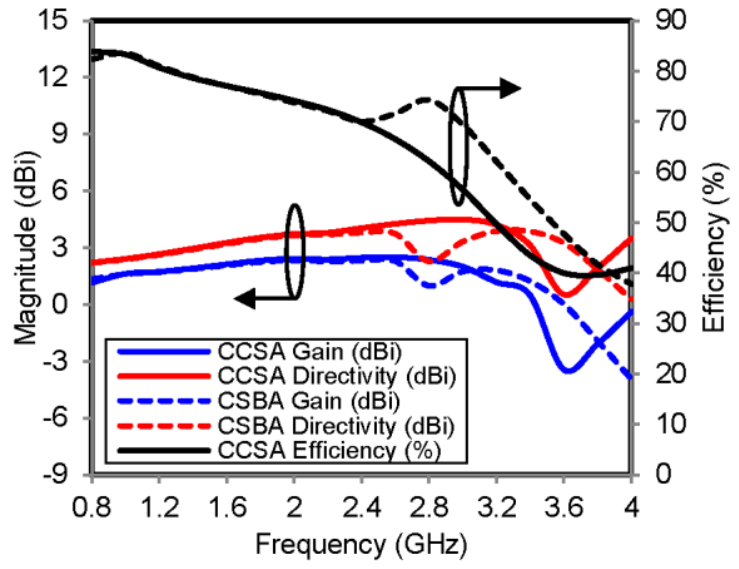

(a)

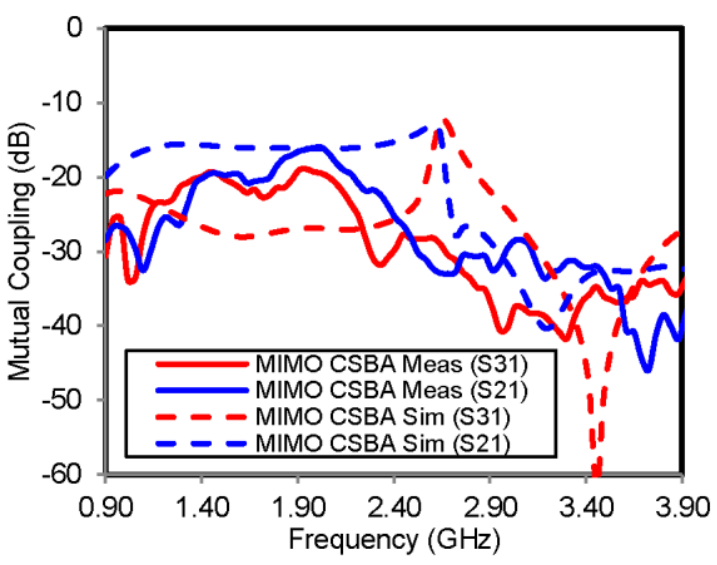

(b)

Figure 9. (a) The comparison gain (dBi), directivity (dBi), Efficiency (\%), (b) The comparison between simulated and measured of mutual coupling $\left(\mathrm{S}_{21}\right)$ and $\left(\mathrm{S}_{31}\right)$ 
Table 2 summarizes the comparison of simulated and measured data of CCSA [Model-1] antenna, CSBA [Model-2] antenna, and MIMO CBSA [Model-3] antenna, in brief. Moreover, the radiation patterns of the proposed antenna are shown in Figure 10(a)-(h). In conclusion, all of these advantages make it particularly valuable in multistandard antenna applications design such as GSM950, WCDMA1800, LTE2300, and WLAN2400.

Table 2. The Comparison of Simulated and Measured Result of CCSA [Model-1] Antenna, CSBA [Model-2] Antenna, and MIMO CBSA [Model-3] Antenna

\begin{tabular}{|c|c|c|c|c|c|c|}
\hline \multirow[t]{2}{*}{ Performace } & \multicolumn{2}{|c|}{$\begin{array}{c}\text { CCSA } \\
{[\text { Model-1] }}\end{array}$} & \multicolumn{2}{|c|}{$\begin{array}{c}\text { CSBA } \\
{[\text { Model-2] }}\end{array}$} & \multicolumn{2}{|c|}{$\begin{array}{c}\text { MIMO CBSA } \\
{[\text { Model-3] }}\end{array}$} \\
\hline & Simulated & Measured & Simulated & Measured & Simulated & Measured \\
\hline Lower frequency $(\mathrm{GHz})$ & 1.093 & 1.094 & 1.051 & 1.090 & 1.061 & 1.095 \\
\hline Upper frequency $(\mathrm{GHz})$ & 2.719 & 2.568 & 3.299 & 3.422 & 3.275 & 3.417 \\
\hline Center frequency (GHz) & 1.906 & 1.831 & 2.175 & 2.265 & 2.168 & 2.256 \\
\hline Bandwidth (MHz) & 1.626 & 1.474 & 2.248 & 2.332 & 2.214 & 2.322 \\
\hline Reflection coefficient $(\mathrm{dB})$ & -16.39 & -15.13 & -17.99 & -17.37 & -17.12 & -17.25 \\
\hline VSWR & 1.35 & 1.42 & 1.28 & 1.31 & 1.32 & 1.33 \\
\hline Mutual coupling $\left(\mathrm{S}_{21}\right)$ & NA & NA & NA & NA & -16.15 & -26.18 \\
\hline Mutual coupling $\left(\mathrm{S}_{31}\right)$ & NA & NA & NA & NA & -27.11 & -26.41 \\
\hline Gain@f=0.95 GHz (dBi) & 1.58 & NA & 1.56 & NA & 0.14 & NA \\
\hline Gain@f=1.85 GHz (dBi) & 3.61 & NA & 2.29 & NA & 3.90 & NA \\
\hline Gain@f=2.35 GHz (dBi) & 2.44 & NA & 2.27 & NA & 4.64 & NA \\
\hline Gain@f=2.45 GHz (dBi) & 2.47 & NA & 2.34 & NA & 4.84 & NA \\
\hline Directivity@f=0.95 GHz (dBi) & 2.34 & NA & 2.32 & NA & 1.47 & NA \\
\hline Directivity@f=1.85 GHz (dBi) & 2.36 & NA & 3.54 & NA & 4.50 & NA \\
\hline Directivity@f=2.35 GHz (dBi) & 3.99 & NA & 3.74 & NA & 5.49 & NA \\
\hline Directivity@f=2.45 GHz (dBi) & 4.09 & NA & 3.84 & NA & 5.16 & NA \\
\hline Efficiency@f=0.95 GHz (\%) & 83.99 & NA & 83.92 & NA & 73.74 & NA \\
\hline Efficiency@f=1.85 GHz (\%) & 75.12 & NA & 74.92 & NA & 87.25 & NA \\
\hline Efficiency@f=2.35 GHz (\%) & 70.10 & NA & 71.25 & NA & 82.23 & NA \\
\hline Efficiency@f=2.45 GHz (\%) & 68.95 & NA & 70.89 & NA & 92.82 & NA \\
\hline \multirow{3}{*}{$\begin{array}{ll} & \text { W }(\mathrm{mm}) \\
\text { Size } & L(\mathrm{~mm}) \\
& H(\mathrm{~mm})\end{array}$} & 63 & 63 & 51.5 & 51.5 & 190 & 190 \\
\hline & 90 & 90 & 90 & 90 & 190 & 190 \\
\hline & 1.6 & 1.6 & 1.6 & 1.6 & 1.6 & 1.6 \\
\hline
\end{tabular}

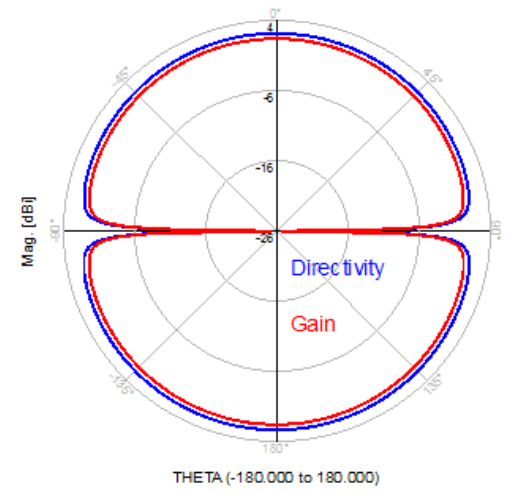

(a)

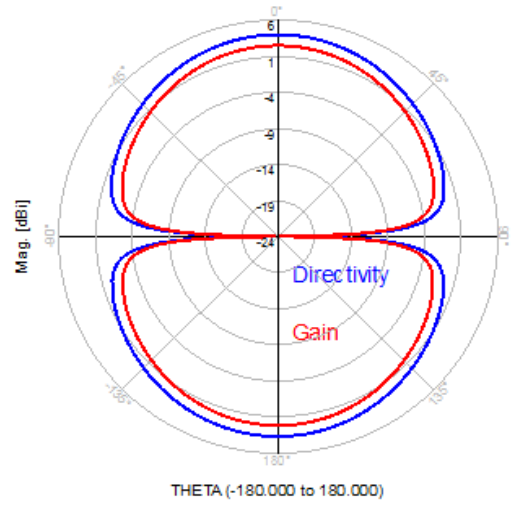

(c)

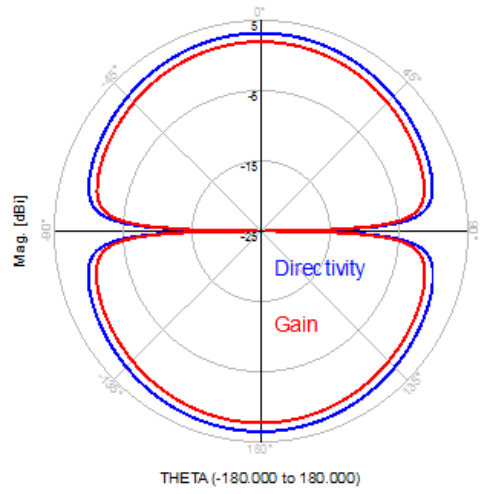

(b)

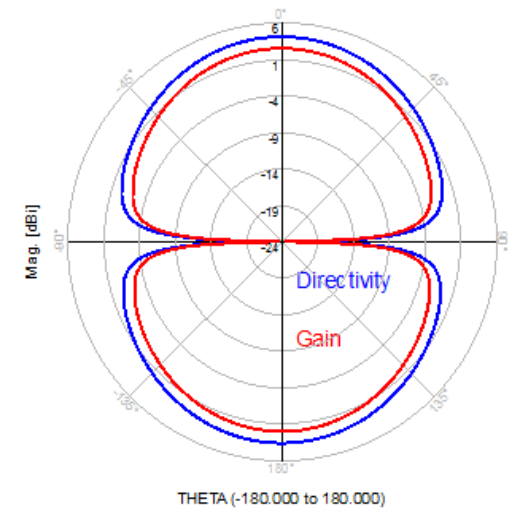

(d) 


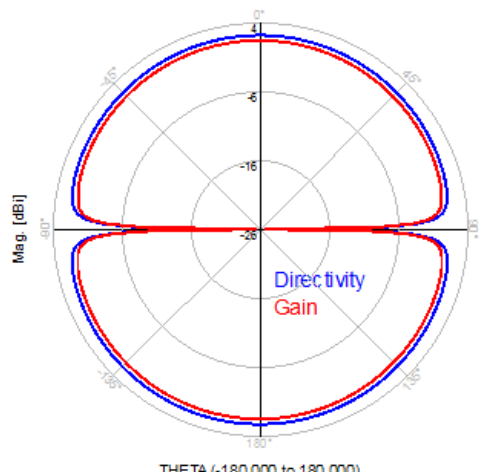

(e)

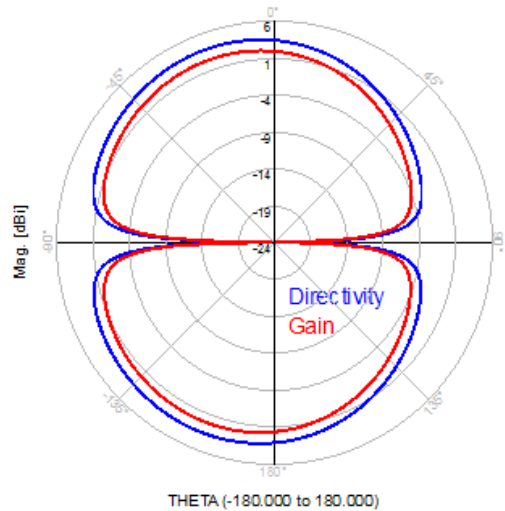

(g)

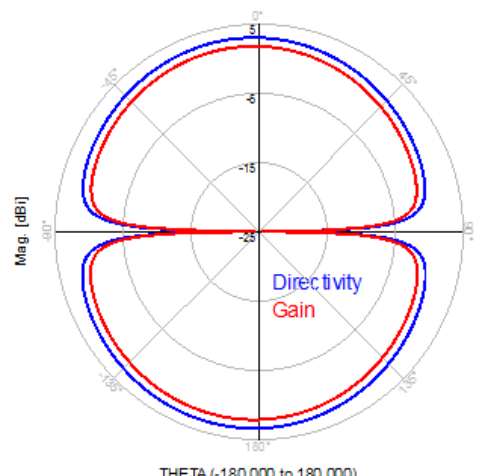

(f)

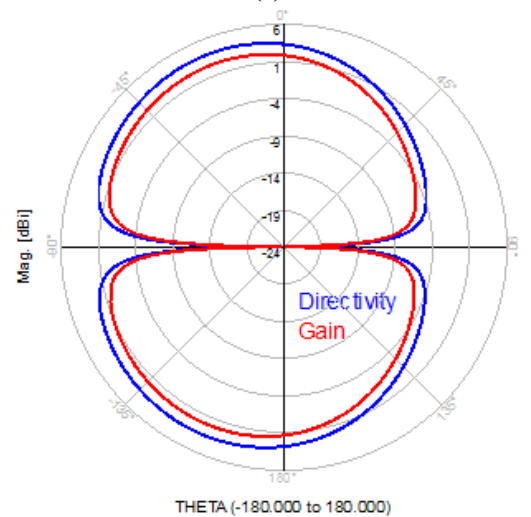

(h)

Figure 10. Gain and directivity of CCSA at frequency (a) $\mathrm{f}=0.95 \mathrm{GHz}$, (b) $\mathrm{f}=1.85 \mathrm{GHz}$, (c) $\mathrm{f}=2.35 \mathrm{GHz}$, (d) $\mathrm{f}=2.45 \mathrm{GHz}$. Gain and directivity of CSBA at frequency (e) $\mathrm{f}=0.95 \mathrm{GHz}$, (f) $\mathrm{f}=1.85 \mathrm{GHz}$, (g) $\mathrm{f}=2.35 \mathrm{GHz}$, (h) $\mathrm{f}=2.45 \mathrm{GHz}$

\section{CONCLUSION}

In order to reduce the antena size and enhance the bandwidth of antena, this paper was proposed the beleved half-cut microstrip structure. Moreover, this research was investigated conventional circular shape antenna (CCSA), circular shaped beleved antenna (CSBA), and MIMO circular shaped beleved antenna (MIMO-CBSA) as Model 1, Model 2, and Model 3, respectively. This antenna was fabricated on FR4 substrate with er $=4.4$, thickness $\mathrm{h}=1.6 \mathrm{~mm}$, and $\tan \mathrm{d}=0.0265$. The numerical simulation has been conducted using Advanced Design System (ADS). The measured result showed that proposed antenna CSBA [Model 2] has wider-bandwidth of $58,2 \%$ and smaller-size of $18.2 \%$ compared to CCSA [Model 1] antenna. Then, after CSBA [Model 2] structure was applied to MIMO $2 \times 2$ [Model 3], the MIMO antenna obtain very good mutual coupling $(<-15 \mathrm{~dB})$. Moreover, the measured results are good agreement with the simulated results. In conclusion, all of these advantages make it particularly valuable in multistandard antenna applications design such as GSM950, WCDMA1800, LTE2300, and WLAN2400.

\section{ACKNOWLEDGEMENTS}

The authors thank the LPPM Universitas Sultan Ageng Tirtayasa (UNTIRTA) and Ministry of Research, Technology and Higher Education, Indonesian Government, KEMENRISTEK DIKTI for the financial support.

\section{REFERENCES}

[1] L. Wang, Z. Weng, Y. C. Jiao, W. Zhang and C. Zhang, "A Low-Profile Broadband Circularly Polarized Microstrip Antenna With Wide Beamwidth," IEEE Antennas and Wireless Propagation Letters, vol. 17, no. 7, pp. 1213-1217, July 2018. doi: 10.1109/LAWP.2018.2839100

[2] Hashim Dahri, et al. "Broadband Resonant Elements for 5G Reflectarray Antenna Design," TELKOMNIKA Telecommunication Computing Electronics and Control, vol. 15 (3), pp. 793-798. 2017. 
[3] Raimi Dewanet., et al "Dual Band to Wideband Pentagon-shaped Patch Antenna with Frequency Reconfigurability using EBGs," International Journal of Electrical and Computer Engineering (IJECE), Vol.8, No.4, pp. 2557-2563. August 2018.

[4] E. Ragab M, "Study on Bandwidth Enhancement Techniques of Microstrip Antenna," Journal of Electrical Systems and Information Technology, vol. 3 (3), pp. 527-531, December 2016. doi: 10.1016/j.jesit.2015.05.003

[5] J. F. Lin and Q. X. Chu, "Enhancing Bandwidth of CP Microstrip Antenna by Using Parasitic Patches in Annular Sector Shapes to Control Electric Field Components," IEEE Antennas and Wireless Propagation Letters, vol. 17, no. 5, pp. 924-927, May 2018. doi: 10.1109/LAWP.2018.2825236

[6] D. S. Marotkar and P. Zade, "Bandwidth Enhancement of Microstrip Patch Antenna Using Defected Ground Structure," International Conference on Electrical, Electronics, and Optimization Techniques (ICEEOT), Chennai, pp. 1712-1716, 2016. doi: 10.1109/ICEEOT.2016.7754978.

[7] Gupta and M. Kumar, "Bandwidth Enhancement of Microstrip Patch Antennas by Implementing Electromagnetic Bandgap (EBG) Structures," Fourth International Conference on Computational Intelligence and Communication Networks, Mathura, pp. 15-18, 2012. doi: 10.1109/CICN.2012.58

[8] R. C. Hadarig, M. E. de Cos, and F. Las-Heras., "Microstrip Patch Antenna Bandwidth Enhancement Using AMC/EBG Structures," International Journal of Antennas and Propagation, vol. pp. 1-6, 2012. doi:10.1155/2012/843754

[9] M. H. Reddy, R. M. Joany, M. J. Reddy, M. Sugadev and E. Logashanmugam, "Bandwidth Enhancement of Microstrip Patch Antenna Using Parasitic Patch," IEEE International Conference on Smart Technologies and Management for Computing, Communication, Controls, Energy and Materials (ICSTM), Chennai, pp. 295-298, 2017. doi: 10.1109/ICSTM.2017.8089172

[10] Lin Peng, Fu-Man Yang and Xing Jiang, "Simple and Electrically Small EZR-MZR Resonator With QuasiIsotropic Pattern," IEEE Journal of Radio Frequency Identification, vol. 1, 2017. doi: 10.1002/mop.30471

[11] P, Ananya., et at., "Bandwidth Enhancement of Microstrip Patch Antenna Using Metamaterials," IOSR Journal of Electronics and Communication Engineering (IOSR-JECE), vol. 8 (4), pp. 5-10. Nov 2013

[12] R. Yang, Y. Xie , D. Li , J. Zhang \& J. Jiang. "Bandwidth Enhancement of Microstrip Antennas with Metamaterial Bilayered Substrates", Journal of Electromagnetic Waves and Applications, vol. 21(15), pp. 2321-2330, 2007. doi: $10.1163 / 156939307783134425$

[13] B. Sudeep, V. Dinesh Kumar., "Bandwidth Enhancement of a Planar Monopole Microstrip Patch Antenna," International Journal of Microwave and Wireless Technologies. vol. 8, issue 2, pp. 237-242. March 2016. doi:10.1017/S175907871400141X

[14] S. Kun Song, Y.Ying-Zeng, Xiao-Bo Wu, and Li Zhang., "Bandwidth Enhancement of Open Slot Antenna With A T-Shaped Stub," Microwave And Optical Technology Letters. vol. 52,no. 2, pp. 390-393. February 2010. doi: $10.1002 / \mathrm{mop}$

[15] M. Nipun K, D. Soma, and V. Dinesh K., "Bandwidth Enhancement of Cylindrical Dielectric Resonator Antenna Using Thin Dielectric Layer Fed by Resonating Slot”. Frequenz. Vol. 70, pp. 381-388. 2016. doi: 10.1515/freq2015-0188

[16] M. Wan Asilah Wan., "Bandwidth enhancement using Polymeric Grid Array Antenna for millimeter-wave application”. Appl. Phys. A. vol. 123:69, 2017 doi: 10.1007/s00339-016-0689-0

[17] Arora C., Pattnaik S.S., Baral R.N. (2018) Bandwidth Enhancement of Microstrip Patch Antenna Array Using Spiral Split Ring Resonator. Advances in Intelligent Systems and Computing, vol 672. doi:10.1007/978-981-10$7512-4$

[18] F. Mohamadi Monavar and N. Komjani., "Bandwidth Enhancement Of Microstrip Patch Antenna Using Jerusalem Cross-Shaped Frequency Selective Surfaces By Invasive Weed Optimization Approach”. Progress In Electromagnetics Research, vol. 121, pp. 103-120, 2011.

[19] Z. Miers, H. Li and B. K. Lau, "Design of Bandwidth-Enhanced and Multiband MIMO Antennas Using Characteristic Modes," IEEE Antennas and Wireless Propagation Letters, vol. 12, pp. 1696-1699, 2013. doi: 10.1109/LAWP.2013.2292562

[20] Y. Wen, D. Yang, H. Zeng, M. Zou and J. Pan, "Bandwidth Enhancement of Low-Profile Microstrip Antenna for MIMO Applications," IEEE Transactions on Antennas and Propagation, vol. 66, no. 3, pp. 1064-1075, March 2018. doi: 10.1109/TAP.2017.2787542

[21] Edward J. Rothwell and Raoul O. Ouedraogo., "Antenna Miniaturization: Definitions, Concepts, and a Review With Emphasis on Metamaterials," Journal of Electromagnetic Waves and Applications, doi: 10.1080/09205071.2014.972470

[22] H. Mosallaei and K. Sarabandi, "Antenna Miniaturization and Bandwidth Enhancement Using a Reactive Impedance Substrate," IEEE Transactions on Antennas and Propagation, vol. 52, no. 9, pp. 2403-2414, Sept. 2004. doi: 10.1109/TAP.2004.834135

[23] A. Toktas, "G-shaped Band-Notched Ultra-Wideband MIMO Antenna System for Mobile Terminals," IET Microwaves, Antennas \& Propagation, vol. 11, no. 5, pp. 718-725, 2017. doi: 10.1049/iet-map.2016.0820

[24] M. S. Sharawi, S. K. Podilchak, M. T. Hussain and Y. M. M. Antar, "Dielectric Resonator based MIMO Antenna System Enabling Millimetre-Wave Mobile Devices," IET Microwaves, Antennas \& Propagation, vol. 11, no. 2, pp. 287-293, 1 29. 2017. doi: 10.1049/iet-map.2016.0457

[25] H. T. Hu, F. C. Chen and Q. X. Chu, "A Wideband U-Shaped Slot Antenna and Its Application in MIMO Terminals," IEEE Antennas and Wireless Propagation Letters, vol. 15, pp. 508-511, 2016. doi: 10.1109/LAWP.2015.2455237 
[26] T Pramendra, P Sharma, T Bandopadhyay. "Gain Enhancement of Circular Microstrip Antenna for Personal Communication Systems," International Journal of Engineering and Technology. vol. 3(2), pp. 175-178. 2011.

[27] Firmansyah, T. et al.,"Bandwidth and Gain Enhancement of MIMO Antenna by Using Ring and Circular Parasitic With Air-Gap Microstrip Structure," TELKOMNIKA Telecommunication Computing Electronics and Control. vol. 15 (3), pp. 1155-1163. 2017.

[28] Firmansyah, T. et al., "Dual-Wideband Band Pass Filter Using Folded Cross-Stub Stepped Impedance Resonator," Microwave and Optical Technology Letters, vol. 59 (11), pp. 2929-2934, November 2017.

[29] Bahl, Inder, Lumped Elements for RF and Microwave Circuits. Norwood: Artech House, Inc, 2003.

[30] D. Pozar Microwave Enginering, Fourth Edition, Wiley, 2011. 